\title{
ASPECTS OF LOCALNESS: A PILOT STUDY OF KIOSK AND GRILL FOOD NAMES IN FINLAND
}

Keywords: localness, commercial names, product names, company names, Finland

\section{INTRODUCTION}

One special function of commercial names is to direct consumer choices, since a name can cast a referent in a positive light (Ainiala et al., 2016, pp. 210-211). Commercial names include names of products and companies, and both are analysed in this article.

Positive images in commercial names are achieved in multiple ways. One solution is to give the referent a name that includes some local element, such as a local place name. It is obvious that if a commercial name includes features of local language, these types of names are "correctly" perceived and interpreted only by a local language community and by a local culture (Sjöblom, 2013, p. 5). Thus, local features that appear in commercial names may be desirable if the products by the company principally target local customers. As earlier studies have demonstrated, localness and regionalism are visible in many commercial names (e.g., Bergien, 2012; Zilg, 2013). This type of names may convey a feeling of belonging to a certain region (Zilg 2013, p. 395), and they can impart a sense of authenticity.

The focus of this article is on the names of grill food. ${ }^{1}$ I analyse the names of grill food products and companies in Finland that sell products in kiosks. Grill food names belong to a group of dish names that constitute a special category of proper names which few scholars have analysed (however, for example, see Lick \& Wochele, 2012; Lavric, 2012).

To offer an overall picture of the subject for analysis, I present representative Finnish products and kiosks. More specifically, the study focusses on typical grill kiosks that are privately owned and have their own names and concepts. In other words, kiosks in Finland differ from international or national restaurant chains and

\footnotetext{
${ }^{1}$ I prefer the term grill food instead of junk food.
} 
franchising businesses. Finnish kiosks offer products such as hamburgers, meat pies, hot dogs, sausages and various meals, such as makkaraperunat (a dish consisting of fries (peruna 'potato') and fried pieces of sausage (makkara 'sausage'). A kiosk can also offer its own signature product named after the locality. These products will be examined in more detail later in this article. A kiosk is also usually located by the road or in the city centre, for example, at a city or town square. The history of Finnish kiosks dates back to the nineteenth century, and some of the current kiosks have been serving customers for several decades (Mäkinen, 2003).

\section{RESEARCH QUESTIONS AND MATERIAL}

This analysis has two aims. Firstly, I simply determine the number of local names in my material. Secondly, I analyse how these names work as indexes of localness and thus investigate the linguistic characteristics by which the locality is manifested. Whilst discussing the indexes of localness, I also explore a number of claims made by the sociolinguist Barbara Johnstone. She states that particular linguistic forms can index meanings along a variety of dimensions and some forms may index locality and/or, for example, class. These types of linguistic forms can be used in discourses that shape people's senses of place and the social identities associated with place (Johnstone, 2010).

Applying Johnstone's ideas to the commercial names and localness, I define three possible means for a commercial name to index localness. These are: 1) the name includes local dialect or slang, 2) the name includes a local place name or personal name, and 3) the name includes some other reference to the region.

As research material, I have compiled a selection of Finnish grill food kiosks and the menus they offer. I have selected 15 kiosks for my pilot study and searched their names and menus on their websites or Facebook pages. The material includes kiosks from major cities and towns in Finland (Espoo, Tampere, Oulu, Lahti and Kuopio), middle-sized towns (Lappeenranta, Kokkola, Seinäjoki, Tornio, Järvenpää, Kaarina and Kajaani), and from smaller towns and municipalities (Isokyrö, Alavus and Närpes). Although the kiosks are located in different parts of Finland, I will not compare them in this respect because there is insufficient material to conduct an analysis of this type. Nevertheless, to obtain material that is as varied as possible, my objective has been to collect material from kiosks located in various parts of the country and from kiosks located both in major cities and in smaller municipalities. When examining local characteristics represented in names, it is relevant to have material from various parts of the county, that is, to observe several "localnesses". One of the kiosks, which is located in the town of Närpes, has its menu in both Finnish and Swedish, ${ }^{2}$ whereas all the others appear only in Finnish.

${ }^{2}$ Finnish and Swedish are both national languages of Finland, and Swedish is the official language in several municipalities in Ostrobothnia, the Åland Islands, Southwest Finland and Uusimaa. These municipalities are often officially bilingual. 
Whilst selecting the kiosks for my study, for practical reasons, I have mainly only been able to select kiosks that have their own websites or Facebook pages. Finland has many grill food kiosks without websites, which means that the menus they offer are only visible at the kiosks themselves. It would thus have required extensive fieldwork to gather material from these types of kiosks. Otherwise, the kiosks have been selected for analysis somewhat randomly. With the help of the Google search engine, I selected 15 kiosks that have their own websites, and, additionally, included only one kiosk from a single municipality. The material was collected between the years 2017 and 2020 .

Every kiosk has its own menu, and whilst collecting the material, I have excluded all the salads and drinks. After this deletion, the menus on average offer 40 products on sale. The minimum number of the products was 22 and the maximum 54. The entire collection consists of 589 products. It is important to note that the material is restricted, and thus only some observations can be made, but no general tendencies can be claimed. Furthermore, I consider this analysis to be a pilot study which will pave the way for future research.

In the following. I will first identify the names of kiosks and then the product names. I examine the extent to which local features are included in these names and how these names serve as indexes of the localness.

\section{NAMES OF KIOSKS}

Of the 15 names in the material, 13 names can be claimed to represent local characteristics. Therefore, only two names in the material did not index locality. These names are Grilli Katukokki ${ }^{3}$ (Fi. grilli 'grill', katukokki 'street cook'; located in the town of Seinäjoki) and Citygrillen (Swe. grillen 'grill'; located in the town of Närpes). These names provide neither information on the location of the kiosks nor any other knowledge about the local characteristics of the referents. However, they can both be described as referring to something "urban" because they incorporate either the Finnish word katu ('street') or the English word city in them. Even so, these names cannot be interpreted as indexing locality.

As mentioned above, the majority of the kiosk names manifest local characteristics. Of these 13 names, 11 include a local name. Seven kiosk names contain a local place name. These may be names of towns (2 names): Tornion Keskusgrilli (Fi. keskus 'centre', grilli 'grill') and Kokkolan Autogrilli (Fi. auto 'car'). Tornio and Kokkola are Finnish towns, and the town names for these kiosk names appear in the genitive case, following regular name formation in Finnish. Structurally,

${ }^{3}$ The kiosk and product names appear in exactly the form they occur in my material. There are some differences between the names, such as the generic part in names may or may not be written in capital letters. 
town names, such as the place names usually found in these types of commercial names, are classified as the identifying parts of the names (see Ainiala et al., 2016, pp. 233-236; Sjöblom, 2016, p. 460).

Besides town names, three neighbourhood names are included in these kiosk names. For example, Pietolan Grilli (at the town of Järvenpää) includes the neighbourhood name of Pietola and is thus similar in formation to previous names that incorporate town names. In a similar vein, the kiosk name Lähde-Kioski (at the town of Lahti) does not include a full neighbourhood name but only a part of it. This kiosk is situated at the neighbourhood of Villähde. The Finnish word lähde means 'spring (a place where water naturally flows out from the ground)', and thus the kiosk name may be interpreted as referring to a spring in general instead of consisting of a local place name. The third kiosk that incorporates a neighbourhood name is Pizpala. The semantic connection of this name to its referent may be described as a compressed meaning relationship because several different semantic contents have been condensed in the name (Ainiala et al., 2016, pp. 241-243; Sjöblom, 2016, p. 461). The kiosk is situated in the neighbourhood of Pispala in Tampere. Thus, the kiosk name contains the letter $z$ instead of $s$. The beginning of the name, Piz-, may refer to the word pizza, and this interpretation is most likely reinforced because the end of the name, pala, can be interpreted as a Finnish word meaning 'slice'. This means that the kiosk name could be understood as 'a pizza slice', and the kiosk does indeed have pizza slices on its menu. This type of wordplay with name elements and the attempt to evoke several potential motivations is not unusual in commercial names. These names have been planned to function in a commercial context where the perspectives of marketing, advertising and consumers must be taken into account (Sjöblom, 2010).

Two kiosk names refer to street names instead of town or neighbourhood names, and they therefore provide information on the location of the kiosks with respect to particular streets. Neither of these names includes a full street name but only a specific part of the name. These names are: Harrin Grilli-Kahvio (Fi. kahvio 'cafe''; in the town of Alavus) and Hulkon Grilli (in the town of Kuopio). The former kiosk is located on a street called Harrintie ('Harri's Street') and the latter on a street called Hulkontie ('Hulkko's Street'). What is evident in these modifying parts of street names is that they are both personal names: Harri is a first name and Hulkko a surname. Personal names obey Finnish grammar rules and occur in the genitive case in these street and kiosk names. The socio-cultural function of these kiosk names can be considered to constitute individualising. This function combines company names with personal names and may personify the business (Ainiala et al., 2016, pp. 243-244). In other words, in addition to providing information on kiosk location, these names could be interpreted as the kiosks belonging to people named Harri or Hulkko. 
A kiosk name therefore usually includes a local place name, be it a town, a neighbourhood or a street name, and provides information on the location of the kiosk. Moreover, it indexes these names as local and can offer people a sense of regionalism and even authenticity. It is also important to note that these names are often constructed so that they allow several possible interpretations and motivations. However, this article focusses on the various means used to express localness through the use of names.

As explained above, most of the kiosk names that contain a local name also have a place name. Besides place names, there are four other local names involved. To begin with, three personal names occur in kiosk names: Mantan Grilli (in the town of Kajaani), Sepen Grilli (in the town of Kaarina) and Janskun Grilli $\&$ Kioski (in the town of Oulu). They are all unofficial, hypocoristic names (see Ainiala et al., 2016, pp. 130-132). As elements of these kiosk names, the name Manta derives from a female name Amanda, the name Sepe from a Finnish male name Seppo and the name Jansku from a Finnish female name Janina. In kiosk names, these personal names refer to the names of the kiosk owners and are in the genitive case. These names have been used in kiosk names instead of official personal names because informal, cosy and even intimate feelings are attempted to evoke. Thus these names thus have a socio-cultural function and an individualising one (Ainiala et al., 2016, pp. 243-244).

A special case among the kiosk names that contain a local name is Tuen Grilli. The owner of the kiosk is a support community called Saipan Tuki. Saipa is a widely known abbreviation of the name of an ice hockey team and tuki, tuen in the genitive case, is a Finnish word meaning 'support'. The kiosk is located in the town of Lappeenranta, which is the hometown of the abovementioned team. Therefore, the kiosk name provides information on the kiosk owner but does not necessarily open up to people who do not know the support community. Nevertheless, the kiosk name offers a clear index of localness.

Finally, two special names occur in the group of kiosk names that index localness. These names do not contain a local proper name but include other types of references to the region. The first name is Grilli-Kahvio Karoliini (Fi. kahvio 'cafe'). The Finnish word karoliini refers to the Caroleans who were the soldiers of two Swedish kings, Charles XI and Charles XII during the Great Northern War (1700-21). ${ }^{4}$ The grill in question is located in the municipality of Isokyrö in Ostrobothnia, where the battle of Napue between the Caroleans, that is, the Swedish Empire, and the Tsardom of Russia took place in 1714. The grill even has a picture of the Carolean soldiers on its website ${ }^{5}$ and a relief of Caroleans situated near the kiosk.

\footnotetext{
${ }^{4}$ https://en.wikipedia.org/wiki/Caroleans (Retrieved May 14, 2020).

${ }^{5}$ http://grilli-kahviokaroliini.fi/ (Retrieved May 14, 2020).
} 
In this manner, the kiosk incorporates local history in its marketing. Many of the product names this kiosk offers also exploit the exceptional history of the region, and these will be discussed later in this article.

The other kiosk name including a local reference is Puosun Grilli (in the city of Espoo). This reference is not as direct and explicit as in the previous name. Puosun Grilli includes the Finnish word puosu 'a boatswain, deck boss'. In Finnish, the word puosu is particularly used in the context of seafaring and the corresponding standard Finnish variant is pursimies. In the kiosk name, the word puosu is probably used in reference to the location of the kiosk and of the region by the sea. The neighbourhood is indeed located near the coast of the Gulf of Finland. The use of the word puosu instead of the word pursimies may have similar motivation as the use of hypocorisms instead of official first names in the names of kiosks. A kiosk name may therefore evoke cosy and quaint associations as well as a sense of proximity.

After analysing the 15 kiosk names, we may conclude that local features are strongly represented in most of them. Additionally, it is important to note that the language of the names is Finnish but with one exception. The Swedish name Citygrillen belongs to a kiosk that is located in a Swedish-speaking town and therefore reflects locality in terms of this language. Whilst the modifier of the name, City, is certainly English, it is used in many European languages (cf. Ainiala et al., 2016, p. 239). Of all the kiosk names, none were in English or had quasi-lingual names (on the language of the commercial names, see Ainiala et al., 2016, pp. 238-241; Sjöblom, 2016, pp. 462-463). Thus, even the languages of these names indicate localness, that is, Finnishness.

\section{NAMES OF PRODUCTS}

As mentioned above, my study material consists of 15 Finnish grill food kiosks with their menus. These menus include a total of 589 products. However, only a small subset of these can be defined as proper names. I will not go in detail at this point to explain or reflect on the basis for the division between proper names and appellatives (for example, see Ainiala et al., 2016, pp. 13-16; Nyström, 2016). A concrete solution in the present analysis has been to classify all the expressions that occur in product "names" as appellatives when they constitute normal Finnish words and are included in the Finnish dictionary. ${ }^{6}$ After this classification, only a small portion (14 percent) of the material remained and could be defined as proper names. A total of 505 products ( 86 percent) on the menus are classified as appellatives. Examples of these are: hampurilainen 'hamburger',

\footnotetext{
${ }^{6}$ https://www.kielitoimistonsanakirja.fi/ (Retrieved May 14, 2020).
} 
ananashampurilainen 'pineapple hamburger', tuplaburger 'double burger', nakki 'frankfurter' and porilainen. The latter has no English equivalent. In Finnish, the word porilainen has two meanings: 1 . of or pertaining to the city of Pori or its people; 2. 'hamburger-style snack' (slice of sausage in the middle). ${ }^{7}$ Thus, the word porilainen derives from the city name Pori but the grill food dish cannot be interpreted as a proper name nor does it currently index localness. Porilainen snacks are sold throughout the country.

Of the 589 products, 84 (14 percent) can be interpreted as including a proper name, but it is not always easy to define whether or not a local feature is visible in the name. Nonetheless, I have attempted to analyse these names to the best of my knowledge, and as a member of the Finnish society. As a result, I have been able to classify 46 of these 84 names as local. Examples of other, non-local product names are: Keisari 'emperor', Alokas 'recruit', Isoveli 'big brother', Pikkuveli 'little brother', Pelastajan burgeri 'rescuer's burger' and Grillin erikoinen 'grill's special'.

In the following, I will categorise these 46 names in the groups by following the model already applied to kiosk names.

As in kiosk names, most local product names include a local name. Of the 46 product names that index locality, 38 names belong to this group. I will not present all of these names but offer illustrative examples instead. To begin with, the name of the kiosk is often present in the product names. For example, the menu of Hulkon Grilli offers the products called Hulkonlihis (Hulkko's; Fi. lihis: a colloquial word for lihapiirakka 'meat pastry'), Hulkonhampurilainen (Fi. hampurilainen 'hamburger'). In addition, the kiosk named Harrin Grilli sells Harrin Burger ('Harri's burger') and Iso Harri (iso 'big'). In analysing kiosk names, these two names were found to have an individualising function by containing a human actor, and accordingly, these product names have a similar function. When a customer buys Harrin Burger (Harri's burger), he or she might imagine that it is a burger made by Harri. Another kiosk name already presented above is Grilli-Kahvio Karoliini. One of the products it has on its menu is called Karoliinilainen ('of or pertaining to the kiosk Karoliini').

In addition, the kiosk going by the name of Keskusgrilli (Fi. keskus 'centre') sells a product called Kesen Mättö (Fi. mättö 'nosh'). Kese is an unofficial name for the kiosk itself, and thus this product name expresses two types of local features: a local place name and local slang. Somewhat comparable names are the product names Krossin Kinnas and Laasmäen Lapanen sold at the kiosk of Sepen Grilli. Krossi and Laasmäki are parallel names for a neighbourhood in the town

${ }^{7}$ https://mot.it.helsinki.fi/ (Retrieved May 14, 2020); https://en.wikipedia.org/wiki/Porilainen (Retrieved May 14, 2020). 
of Kaarina in Southwestern Finland. The Finnish words kinnas and lapanen, in turn, mean 'mitten'. They are both dialect words and these product names therefore feature local dialect, as well as local place names.

The kiosk Citygrillen in the bilingual town of Närpes has a bilingual menu, and all the product names are listed on the menu both in Swedish and in Finnish. One of the products this kiosk sells is called Kåtnäsburgare in Swedish and Kåtnäshampurilainen in Finnish. Kåtnäs is the name of a residential area in Närpes, and thus this product name indexes localness in a highly explicit manner.

Whilst providing examples of the appellatives on kiosk menus, I mentioned the famous Finnish product porilainen. As an analogy to it, some kiosks have products called Nastolalainen, Kokkolalainen or Alavutelainen on their menus. Contrary to porilainen, these words are to be classified as proper names. They are unique words in a sense that they are only found in these local kiosks that sell the products in question. For example, Kokkolalainen is sold only in the kiosk Kokkolan Autogrilli in the town of Kokkola. Nastolalainen, in turn, includes the old parish name Nastola, and the Nastola region currently belongs to the town of Lahti. This product is sold in the kiosk called Lähde-Kioski.

Let us now proceed to the product names that contain local personal names. The kiosk called Sepen Grilli (Sepe: a personal name, a hypocorism) features products called Sepen Sattuma (Fi. sattuma 'chance') and Sepen Bravo on its menu. Likewise, the kiosk Mantan Grilli (Manta: a personal name, a hypocorism) has products called Mantan erikoinen (Fi. erikoinen 'special') and Mega Manta on its menu. Hence, these product names not only provide a reference to the kiosk location, but they also contain a local personal name.

Other examples of product names with a personal name are Pirjon erikoinen, Petterin erikoinen and Virtasen Erikoinen. The Finnish word erikoinen means 'special', and Pirjo is a female first name, Petteri a male first name and Virtanen a surname. These are most likely the personal names of the owners of these kiosks. A slightly more exceptional case is the product name Bottas-Burger. This contains the surname of the famous Finnish Formula driver, Valtteri Bottas. The kiosk selling this product is situated in the town of Lahti where Bottas grew up. Hence, this product name can be interpreted to be a tribute to a local celebrity.

Among kiosk names, not a single name features local dialect or slang. This is not, however, the case in the names of products. A few of the names mentioned above included local dialect words (Laasmäen Lapanen, Krossin Kinnas) or a slang word (Kesen Mättö). In addition, there are three unique dialectal names of the products sold in the kiosk Sepen Grilli in the town of Kaarina: Mul kans ('to me also'), Simmonen tapaus ('that kind of a case') and Tuliaanen ('present; bring back'). As is evident, these names in local dialect comprise a special group among 
the product names. In terms of semantics, these names also represent meanings and associations that are suitable for the grill food products. In some cases, they are considered humorous and playful names.

The last category among product names consists of names that include some other reference to the region. These five names refer to the products sold in the kiosk named Grilli-Kahvio Karoliini which is located in the municipality of Isokyrö. The names of these products comprise a consistent group that derives its inspiration from a historical episode, a battle that was fought in the Great Northern War of 1714. The names in question are: Mehevä lataus ('juicy loading (of a gun)'), Tykkimiehen suutari ('cannoneer's dud'), Tykkimiehen unelma ('cannoneer's dream'), Aleksanterin annos ('Alexander's portion') and Suusta ladattava ('muzzleloader'). This type of thematic naming is uncommon in the names of grill food products. In this case, the local characteristics are strongly and uniformly manifested.

\section{CONCLUSION}

This pilot study analyses the names of Finnish grill food kiosks and products with the material of 15 kiosk names and 84 product names. I have attempted to determine their number and the manner in which these names represent local features and thus serve as local indexes. Of the 15 kiosk names, the vast majority, 13 names, can be interpreted as manifesting local characteristics. The names of kiosks often include a local place name. In product names, more than half (46 names) of all the names (84) are to be construed as local indexes. However, it is important to remember that the vast majority of the products do not have a proper name but instead an appellative. Most of the local product names include a place name, but personal names are also rather common. In addition, local dialect or slang is also visible in the product names. Another type of reference to the region is made in two kiosk names and in some of the product names on the menu of another kiosk. These names constitute a special case and reflect the creative means employed in their expression of local history.

To summarise, the Finnish names of grill food kiosks and products in my data serve as indexes of localness in three ways: they may include names of local places and people, they can include local dialect or slang, or they can refer to the local history. A single name may sometimes include two of these indexes of localness. All the names under scrutiny in this analysis were Finnish or Swedish and they therefore represent the national languages of the country.

Besides local characteristics, the names of grill food kiosks and products can often be described as informal, familiar and even intimate or humorous. These 
names shape people's sense of place and the social identities associated with them. For further study, it would be of interest to analyse some other naming categories and compare them to the names of grill food products and kiosks.

The data in this study were limited and the analysis was therefore defined as a pilot study for future research. To achieve a more comprehensive picture, further analysis on a wider data set is needed. This pilot study consulted the websites and Facebook pages of the kiosks. As relatively few grill food kiosks in Finland have websites, additional material can be obtained by visiting kiosks. A questionnaire could also be sent to kiosks. In the next phase of research, I intend to take photos of the kiosks and their menus, combining onomastic analysis with linguistic landscape studies. This will allow us to deepen our understanding of the role of various languages, linguistic characteristics and other local motives through aspects such as pictures, colours and logos that manifest localness.

\section{REFERENCES}

Ainiala, T. (2013). Stadi and Hesa: Helsinki slang names as commercial names. In P. Sjöblom, T. Ainiala \& U. Hakala (Eds.), Names and cultures in a commercial environment (pp. 173-184). Cambridge: Cambridge Scholars Publishing.

Ainiala, T., Saarelma, M., \& Sjöblom, P. (2016). Names in Focus: An Introduction to Finnish Onomastics. Helsinki: Finnish Literature Society. http://dx.doi.org/10.21435/sflin.17

Bergien, A. (2012). Cultural and regional connotations of company names in local contexts. In R. Boerrigter \& H. Nijboer (Eds.), Names as language and capital. Proceedings Names in the Economy III (pp. 7-12). Amsterdam: Meertens Instituut. http://www.meertens.knaw.nl/nite/ images/pdf/Proceedings_NitE_III.pdf

Johnstone, B. (2010). Indexing the Local. In N. Coupland (Ed.), Handbook of Language and Globalization (pp. 386-405). Oxford: Oxford University Press.

Lavric, E. (2012). Gastronomastics: towards a rhetoric of dish names on restaurants' menus. In H. Wochele, J. Kuhn \& M. Stegu (Eds.), Onomastics goes Business. Role and relevance of brand, company and other names in economic contexts (pp. 219-223). Berlin: Logos Verlag.

Lick, E., \& Wochele, H. (2012). Croque McDo, CBO and Donut zucchero: A contrastive analysis of product names offered by fast food restaurants in European countries. - R. Boerrigter \& H. Nijboer (Eds.), Names as language and capital. Proceedings Names in the Economy III (pp. 64-74). Amsterdam: Meertens Instituut. http://www.meertens.knaw.nl/nite/images/pdf/ Proceedings_NitE_III.pdf

Mäkinen, A. (2003). Puistojen koristus ja katutilan kaunistus - Helsingin kioskien historiaa [The decoration of parks and beautification of streets. The history of kiosks in Helsinki]. Tieteessä Tapahtuu, 21(2), 19-24. https://journal.fi/tt/article/view/57200

Nyström, S. (2016). Names and meaning. In C. Hough (Ed.), The Oxford Handbook of Names and Naming (pp. 39-51). Oxford: Oxford University Press. https://dx.doi.org:10.1093/ oxfordhb/9780199656431.013.5

Sjöblom, P. (2010). Multimodality of company names. Onoma, 43, 351-380.

Sjöblom, P. (2013). Lumia by Nokia, iPhone by Apple: Global or local features in commercial names? In P. Sjöblom, T. Ainiala \& U. Hakala (Eds.), Names and cultures in a commercial environment (pp. 2-14). Cambridge: Cambridge Scholars Publishing. 
Sjöblom, P. (2016). Commercial names. In C. Hough (Ed.), The Oxford Handbook of Names and Naming (pp. 453-464). Oxford: Oxford University Press. http://dx.doi.org/10.1093/ oxfordhb/9780199656431.013.5

Zilg, A. (2013). Tu y yo, Prendi e vai, Saveurs d'ici: How brand names mirror socioeconomic conditions in Romance languages. In O. Felecan \& A. Bugheşiu (Eds.), Onomastics in contemporary public space (pp. 391-404). Cambridge: Cambridge Scholars Publishing.

SUMMARY

This article examines the localness of commercial names in Finland and focusses specifically on the names of grill food kiosks and products. There are two research objectives: firstly, to determine the number of local names that occur in the material, and secondly, to analyse how these names work as indexes of localness. This article explores the claim by sociolinguist Barbara Johnstone that particular linguistic forms can index meanings along a variety of dimensions and some forms may index locality. Furthermore, these types of linguistic forms can be used in discourses that shape people's senses of place and the social identities associated with place.

Of the 15 names of kiosks, almost all names, a total of 13 names, can be interpreted as manifesting local characteristics. Most of the kiosk names include a local place name. Of the product names, more than half ( 46 out of 84 names) are to be construed as describing something local. Although most of the local names in the group of product names include a local place name, personal names are also rather common. In addition, local dialect or slang is also visible in the product names. Another type of reference to a region appears in two kiosk names and in some of the product names. These names constitute a special case and demonstrate how local history can be incorporated in names creatively. 